\title{
Comparative Evaluation of the Efficacy of Novel Root Canal Irrigation Techniques on Reduction of Enterococcus faecalis Count: An In Vitro Study
}

\author{
Sabari Murugesan ${ }^{1}$, Arasappan Rajakumaran ${ }^{2}$, Buggaveeti Pradeep Kumar ${ }^{3}$, Arumugam Balatandayoudam ${ }^{4}$, \\ Purushotham Mohankumar ${ }^{5}$, Bharath Naga Reddy ${ }^{6}$
}

\begin{abstract}
Aim and objective: To compare the effectiveness of three irrigation systems, namely, Endovac system, Max I probe, and Navitip FX, in reduction of Enterococcus faecalis population from the root canal using agar diffusion method.

Materials and methods: Fifty-five extracted intact human permanent maxillary anterior teeth were selected for this study. In group I, root canals were irrigated using brush covered 30-gauge NaviTipFX. Ultradent in group II root canals was irrigated using brush covered 30-gauge Max-IProbe Dentsply. In group III, root canals were irrigated using Endoactivator, Dentsply. In group IV, root canal was irrigated by using the Endovac system Sybronendo. The steps followed in the study include preparation of specimen, contamination of the samples followed by conduction of testing procedures with implementation of appropriate irrigation protocols, and sampling procedures.

Results: Data were subjected to statistical analysis to interpret the significant differences among various irrigation systems. One-way analysis of variance, Post hoc Tukey tests were used for statistical analysis in the present study. Among the experimental groups, group IV showed statistically significant difference in reduction of $E$. faecalis. There were no statistical differences between them in reduction of $E$. faecalis in group I and group II compared and represented in Tables 1 and 2.

Conclusion: All four irrigation delivery systems have been found to be effective in the reduction of E. faecalis. Endovac showed comparable efficacy in reduction of colony-forming units to that of other delivery systems used in the study. The result has to be validated with in vivo studies and clinical trials of larger sample size.

Clinical significance: Selection of appropriate irrigation system capable of disinfection of canal complexities in apical third with less adverse effects is essential for good clinical success of endodontic treatment.

Keywords: Dynamic irrigation needle irrigation, E. faecalis endoactivator, Endovac.

The Journal of Contemporary Dental Practice (2020): 10.5005/jp-journals-10024-2966
\end{abstract}

\section{INTRODUCTION}

The primary objective of nonsurgical endodontic treatment relies in eradication of microbial infection and preservation of vitality of pulp tissue. Endodontic success relies on the implementation of "endodontic triad," which includes effective instrumentation, disinfection, and obturation. ${ }^{1}$

The complexity of the canal anatomy with fins, lateral canals, and apical deltas makes it inaccessible for instrumentation. Disinfection protocols comprise of removal of residual tissue, microbes, and debris to reduce the bacterial load. ${ }^{2}$

The root canal flora is dominated by obligate anaerobic bacteria with mixed population. Enterococcus faecalis has been associated with secondary infections of the failed endodontic treatment. ${ }^{3}$ The unique feature of the bacteria depends on the distance traveled from the surface to the internal aspects of the radicular dentin. ${ }^{4}$

The study has been designed to review the efficacy of conventional irrigation system on reduction of bacterial load with a novel irrigation system. ${ }^{5}$ Measures to improve the replenishment and exchange of irrigant that arises due to vapor lock effect in the apical third of the root canal system has been initiated. ${ }^{6}$

Dynamic irrigant activation system comprises of manual and machine-assisted activation devices. Manual irrigation techniques tested in our study includes Max I probe and Navitip FX, which works on the principle of delivering the irrigant with positive pressure in the apical third of the root canal system. ${ }^{7}$
${ }^{1}$ Department of Restorative Dental Sciences, College of Dentistry, Jazan University, Jazan, Kingdom of Saudi Arabia

${ }^{2}$ Department of Conservative Dentistry and Endodontics, Sri Ramachandra Faculty of Dental Science, Sri Ramachandra Institute of Higher Education and Research, Chennai, Tamil Nadu, India

${ }^{3}$ Department of Conservative Dentistry and Endodontics, Mamata Dental College and Hospital, Khammam, Telangana, India

${ }^{4}$ Department of Oral and Maxillofacial Surgery, Sri Venkateshwara Dental College, Ariyur, Puducherry, India

${ }^{5}$ Department of Conservative Dentistry and Endodontics, Sathyabama Dental College and Hospital, Chennai, Tamil Nadu, India

${ }^{6}$ Department of Conservative Dentistry and Endodontics, Adhiprasakthi Dental College and Hospital, Tamil Nadu Dr. MGR Medical University, Melmaruvathur, Tamil Nadu, India

Corresponding Author:Bharath Naga Reddy, Department of Conservative Dentistry and Endodontics, Adhiprasakthi Dental College and Hospital, Tamil Nadu Dr. MGR Medical University, Melmaruvathur, Tamil Nadu, India, Phone: +91 9444792260, e-mail: drbharathendo999@gmail.com

How to cite this article: Murugesan S, Rajakumaran A, Kumar BP, et al. Comparative Evaluation of the Efficacy of Novel Root Canal Irrigation Techniques on Reduction of Enterococcus faecalis Count: An In Vitro Study. J Contemp Dent Pract 2020;21(12):1379-1383.

Source of support: Nil

Conflict of interest: None

(c) Jaypee Brothers Medical Publishers. 2020 Open Access This article is distributed under the terms of the Creative Commons Attribution 4.0 International License (https://creativecommons.org/licenses/by-nc/4.0/), which permits unrestricted use, distribution, and non-commercial reproduction in any medium, provided you give appropriate credit to the original author(s) and the source, provide a link to the Creative Commons license, and indicate if changes were made. The Creative Commons Public Domain Dedication waiver (http://creativecommons.org/publicdomain/zero/1.0/) applies to the data made available in this article, unless otherwise stated. 
The main advantage of Maxi I probe is that it has side vented needle delivering the irrigant, laterally aiding in penetration into the canal aberrations. The main disadvantage of NaviTipFX is that it delivers the irrigant short of apex.

Machine-assisted agitation devices such as Endoactivator System (EA) uses sonic energy for activation of irrigant and has been found to have canal free from debris. The compact design enhances the effective delivery of irrigant into the canal complexities without causing any alterations to the dentin substrate.

The Endovac system works on the negative pressure principle to suck out debris and aids in cleaning the prepared canal with less potential of irrigant leakage. The major disadvantages of Endovac system is related to technique sensitivity, difficulty in sterilization of device, and cost.

The study was designed in such a way to compare the different concepts, such as positive pressure vs negative pressure and irrigant activation concepts and its ability to assess the efficacy in reduction of $E$. faecalis count.

The aim of this in vitro study was to compare the effectiveness of three irrigation systems, namely, Endovac system, Max I probe, and Navitip FX in reduction of $E$. faecalis population.

\section{Materials and Methods}

Sixty permanent maxillary incisors extracted for prosthodontic purposes were selected for this study. Teeth were debrided with ultrasonic scaler tips. Access cavity preparation was done with no. 2 round burs.

Root canal procedures were done in department of conservative dentistry and endodontics by the primary investigator, and colony-forming units counts were done in the microbiological laboratory by the microbiologist after blinding the materials used for the study.

Patency was established with 10 size K-file. Working length was standardized to $20 \mathrm{~mm}$. The apical enlargement was done till 25 size, and the apical foramen was sealed with Type II GIC. The teeth were mounted in blocks made of self-cure resin. The samples were sterilized in autoclave for 20 minutes at $121^{\circ} \mathrm{C}$.

\section{Contamination of the Specimen}

ATCC 29212 was used in the study and grown in trypticase soy broth for 24 hours. A ratio of 1:5 was employed for preparation of suspension of $E$. faecalis. The inoculation of the sample was done using sterile $1-\mathrm{mL}$ syringe and carried to the entire root canal system with help of sterile K-type file. A rectangular surgical tray was used for placement of blocks and incubated at $37^{\circ} \mathrm{C}$ for 7 days in $100 \%$ humidity.

\section{Testing Procedures}

After 7 days of experimental contamination, the study was designed in such a way and segregated into four experimental groups of 15 based on the irrigation technique employed.

Criteria for grouping the samples along with the irrigation techniques employed are as follows

- In Group I, samples were irrigated by using brush covered 30-gauge NaviTipFX.Ultradent

- In Group II, samples were irrigated by using brush covered 30-gauge Max-I-Probe Dentsply

- In Group III, samples were activated using Endoactivator irrigation system Sybronendo
- In Group IV, samples were irrigated by using the Endovac system Dentsply

All the experimental groups were irrigated with $3 \% \mathrm{NaOCl}$ (sodium hypochlorite) and 17\% EDTA.

\section{Irrigation Protocols}

In group l, the irrigation was done with $2 \mathrm{~mL}$ of $\mathrm{NaOCl}$ using a 30-gaugeNaviTipFX at the end of each instrumentation. In group II, the irrigation was done with $2 \mathrm{~mL}$ of $\mathrm{NaOCl}$ using a 30-gauge Max-i-probe.

The position of the needle was ensured to be $2 \mathrm{~mm}$ short of apex and moved in up and down motion to prevent the extrusion of the solution. After the usage of F4 Instrument, irrigation was done with $3 \% \mathrm{NaOCl}$ for 30 seconds followed by $17 \%$ EDTA for 30 seconds, and again with $3 \% \mathrm{NaOCl}$ for 30 seconds.

In group III, the irrigation protocols were similar to that of groups I and II, and the tip size was kept as 35 with 4\% of taper for irrigant activation.

The activation was done for 30 seconds with $2 \mathrm{~mm}$ short of apex. The cleanliness of the canal was ensured with irrigation of saline solution followed by drying with paper points. The activation of irrigant was repeated.

In group IV, the canal was loaded with irrigant throughout the procedure.

Macro-irrigation cycle: The irrigant delivery was done with master delivery tip at the end of instrumentation. The macroirrigation was done using $3 \% \mathrm{NaOCl}$ for 30 -second period. The coronal third of the canal was irrigated with master delivery tip. The macro-cannula was taken in and out and kept $4 \mathrm{~mm}$ short of apex.

Micro irrigation cycle: Three cycles of micro irrigation was carried with microcannula placed at WL for 6 seconds. This was followed by sequence of irrigation with placement of microcannula at $2 \mathrm{~mm}$ from the WL for 6 seconds and reverted back to WL for 6 seconds.

The in and out motion was done for 30 seconds with 18 seconds of active irrigation at working length. Care was ensured to avoid entrapment into the canal system during the handling of microcannula in presence of irrigant. The irrigants employed in first cycle was $3 \% \mathrm{NaOCl}$ as the irrigant, the second cycle employed $17 \%$ EDTA, and the third cycle was completed again with $3 \% \mathrm{NaOCl}$ once again. Excess irrigant was removed periodically.

\section{Sampling Procedures}

The sampling was done with meticulous care by rinsing the canal space with $1 \mathrm{~mL}$ of $10 \%$ sodium thiosulfate to negate the effects of $\mathrm{NaOCl}$ and then with saline. This was followed by evacuation of canal contents with a 1-mL plastic syringe and transferred into tubes containing $1 \mathrm{~mL}$ of sterile saline. The corresponding size paper points was placed at the WL to soak the canal contents and transferred to the tube containing saline. This was followed by agitation in vortex with 10 -fold serial dilutions in saline. Afterward, aliquots of $0.1 \mathrm{~mL}$ were plated onto brain heart infusion agar plate and incubated at $37^{\circ} \mathrm{C}$ for 48 hours. The colony-forming units (CFUs) were numbered after analyzing the dilution factors.

\section{Results}

The data were subjected to various statistical significance to interpret the significant differences among various irrigation systems. 
Table 1: The mean colony-forming units (CFUs)/mL of the irrigants

\begin{tabular}{lrrl}
\hline Groups & Mean & \multicolumn{1}{c}{$S D$} & p value \\
\hline Endovac & 12.00 & 7.746 & 0.000 \\
Endoactivator & 156.00 & 34.056 & \\
Max-i-probe & 210.00 & 53.852 & \\
Navitip Fx & 425.00 & 32.770 & \\
\hline
\end{tabular}

Table 2: Tukey HSD for specific intergroup comparison

\begin{tabular}{ll}
\hline Group & $p$ value \\
\hline Endovac & \\
Navitip FX & 0.000 \\
Max-i-probe & 0.000 \\
Endoactivator & 0.329 \\
Navitip FX & \\
Endovac & 0.000 \\
Max-i-probe & 0.000 \\
Endoactivator & 0.000 \\
Max-i-probe & \\
Endovac & 0.000 \\
Navitip FX & 0.000 \\
Endoactivator & 0.000 \\
Endoactivator & \\
Endovac & 0.329 \\
Max-i-probe & 0.000 \\
Navitip FX & 0.000 \\
\hline
\end{tabular}

One-way analysis of variance (ANOVA) was used to interpret the overall variance among the groups. It was not possible to identify the difference between the various groups with the help of the $p$ values obtained from ANOVA.

To make a comparison of variance within the group, post hoc Tukey was employed. In our study, one-way ANOVA followed by Tukey HSD test showed statistically significant difference among experimental groups related to $E$. faecalis reduction in each group.

Mean E. faecalis count was highest with mean of $425 \times 106$ colony-forming units (CFUs)/mL] in NaviTipFX group.

Mean rank score for $E$. faecalis count was $210 \times 106$ colonyforming units (CFUs)/mL in Max-I-Probe group.

Mean rank score for $E$. faecalis counts was $156 \times 106$ colonyforming units (CFUs)/mL in Endoactivator group.

Mean rank score for $E$. faecalis reduction was lowest with mean $12 \times 106$ colony-forming units (CFUs)/mL] in Endovac group.

Among the experimental groups, group IV showed statistically significant difference in reduction of $E$. faecalis.

There were no statistical differences between them in reduction of $E$. faecalis in group I and group II compared, and the values are represented in Table 2.

\section{Discussion}

The primary etiology of apical periodontitis arises due to localization of microbial agent in the apical portion of the root canal system. The management of irreversible pulpits aims to prevent the progression of infection into periapical region. ${ }^{7}$

Secondary apical periodontitis arises due to the exacerbating of residual bacterial load. The predominant bacteria from the secondary infection include Lactobacilli, Staphylococci, Enterococcus faecalis, and Propionibacterium. ${ }^{8}$

Enterococcus faecalis is a facultative gram-positive anaerobe with a prevalence of $22-77 \%$. It has a potential to modulate the internal $\mathrm{pH}$ by an efficient proton pump. It has the capacity to travel deep in to the dentinal tubules and get lodged into the canal irregularities. The organism exhibits resistance $\mathrm{pH}$ variations and can last in the challenging and tough enivionment. ${ }^{9}$

The anatomical complexity necessitates employment of special mechanical aids to ensure thorough debridement. The mechanical instrumentation removes the necrotic and vital organic tissue and ensures the fulfillment of mechanical objectives. ${ }^{10}$ In this present study, the apical size was prepared with \#40 ProTaper which has taper of 0.09 , and this enlargement helps in placement of microcannula at the working length.

Brunson et al. showed that apical enlargement size was directly proportional to volume of irrigant delivered. The majority of infection control mechanism depends on the irrigation techniques and devices to contribute to the reduction in microbial agents. ${ }^{11}$

The irrigants used for removal of these materials must address both these organic and inorganic components, and the presence of biofilms in the uninstrumented canal can cause treatment failure. $^{12}$

The removal of the inorganic component in the root canal is of primary importance because it allows penetration of the antimicrobial irrigants to areas of the dentin that may harbor bacteria. ${ }^{13}$

Sodium hypochlorite when used alone as an endodontic irrigant lacks action on the inorganic component and the dentinal debris which is formed during instrumentation. ${ }^{14}$

Ethylenediamine tetra-acetic acid (17\% EDTA) acts predominantly on the inorganic portion of the root canal system. It also reduces the hydrophobicity and surface free energy of root dentin thereby reducing the adherence of E. faecalis to dentin. ${ }^{15}$

In the present study, regime of $3 \%$ sodium hypochlorite and $17 \%$ EDTA was used as final irrigation. In positive pressure technique, irrigant is expelled with pressure from the irrigation system.

Conventional syringe irrigation involves above principle to dispense the irrigant through needle of various sizes passively or with agitation. Mechanical flushing action is relatively weak to displace the debris and bacteria from the inaccessible areas and irregularities, thereby making thorough canal debridement difficult. $^{16}$

The replenishment and exchange of irrigant in the apical third and the effectiveness of chemical debridement are dependent on the depth of penetration. ${ }^{17}$

They are less effective in cleaning the apical areas compared to the coronal areas of root canal systems. The close proximity of the needle tip to the apical tissue has a greater chance of apical extrusion of the irrigant. ${ }^{18}$

It is essential to develop delivery systems that improve the irrigant penetration to the inaccessible areas to ensure complete disinfection of the canal system with minimal in periapical tissues. ${ }^{19}$

Recently, NaviTip FX irrigation system has been into the market. The special design feature with brush helps to reach up to the apex and scrub the canal wall while concomitantly delivering the irrigant effectively to apex. ${ }^{20}$ 
Max-I-Probe is an irrigation system with side vented and closeended needle that delivers the irrigant laterally. The above design improves the availability of irrigant and reduces the apical leakage of the irrigant. Vinoth Kumar et al. showed that Max-I-probe was effective in displacing the bacteria from the root canal. ${ }^{21}$

Boutsioukis et al. had a valuable observation and concluded that the exchange of irrigant happens only 1 to $1.5 \mathrm{~mm}$ past a sidevented needle, and the irrigant beyond that point remains stagnant in his computational fluid dynamic model. ${ }^{22}$

The Endoactivator system aids in penetration of an irrigant to inaccessible areas of the root canal system and helps in dislodgement of bacteria. The high-frequency sonic energy causes activation of irrigant and aids in dislodgment of microbes in an efficient manner. Previous studies have shown that more than $50 \%$ of the dentinal tubules remain open and patent. Its ability to create sonic waves in the root canal aids in the removal and reduction of bacteria along with the necrotic tissue debris.

Endovac is an irrigation system that works on the negativepressure principle and has (1) Macrocannula of $0.55 \mathrm{~mm}$ in diameter/0.02 taper (2) Microcannula with diameter of $0.32 \mathrm{~mm}$. Desai et al. compared the safety of different irrigation systems and concluded that Endovac is safe to work at working length. ${ }^{23}$

Heilbronn et al. observed that volume requirements are unique to the delivery system. ${ }^{24}$ In the present study, the Endovac [group IV] showed few numbers of bacterial colonies [with a mean of 12 $\left.\times 10^{6} \mathrm{CFUs}\right) / \mathrm{mL}$ ] and resulted in significant reduction of bacterial load than the other irrigation system.

Group I (Navitip FX) showed comparable reduction in the bacterial load [with a mean of $425 \times 10^{6} \mathrm{CFUs} / \mathrm{mL}$ ] which might be attributed to the scrubbing action of irrigation system. Similar results was reported by Al-Hadlaq et a1. and Zemner et al. who proved that brush-covered irrigation needle was more effective in achieving cleaner canals.

In Group II (Max-i-probe), there was significant reduction in bacteria load with a mean of $\left.210 \times 10^{6} \mathrm{CFUs}\right) / \mathrm{mL}$. The probable reason may be attributed to its design, closed-ended, side-vented channel, which tends to deliver the irrigant laterally.

This unique design creates a turbulence that removed considerable number of bacteria on comparison with the needle irrigation. ${ }^{25}$ Similar results were reported by Vinothkumar et al. who concluded that side vented was clinically effective than other irrigation devices. $^{26}$

Group III Endoactivator group showed with a mean of $156 \times$ 106 colony-forming units (CFUs)/mL that when compared to other experimental group, it was effective in reduction of bacteria from the root canal.

Endovac irrigation system had maximum bacterial reduction, while the Endoactivator system showed comparable result that might be attributed due the differences in principle of irrigation technique along with position of irrigation device which was at the apex for the Endovac system.

\section{Limitations of the Study}

Usage of Endovac system in thin and curved roots in vivo needs to be warranted. Clinical trials investigating the effects in mixed bacterial community are required to determine the efficacy of disinfection protocols of teeth with apical periodontitis. Additionally, further investigations are also necessary test in vivo situation involving more number of clinical parameters.

\section{Conclusion}

It was found that all four irrigation delivery systems have been found to be effective in the reduction of $E$. faecalis. Endovac showed comparable efficacy in reduction of colony-forming units to that of other delivery systems used in the study. The results have to be validated with in vivo studies and clinical trials of larger sample size.

\section{References}

1. Cohen S. Pathways of the pulp. 9th ed., St. Louis: Mosby Elsevier; 2006.

2. Al-Hadlaq SM, Al-Turaiki SA, Al-Sulami U, et al. Efficacy of a new brushcovered irrigation needle in removing root canal debris: a scanning electron microscopic study. J Endod 2006;32(12):1181-1184. DOI: 10.1016/j.joen.2006.07.019.

3. Siqueira Jr JF, Machado AG, Silveira RM, et al. Evaluation of the effectiveness of sodium hypochlorite used with three irrigation methods in the elimination of Enterococcus faecalis from the root canal, in vitro. Int Endod J 1997;30(4):279-282. DOI: 10.1111/j.13652591.1997.tb00708.x.

4. Love RM. Enterococcus faecalis-a mechanism for its role in endodontic failure. Int Endod J 2001;34(5):399-405. DOI: 10.1046/j.13652591.2001.00437.x.

5. Tay FR, Gu LS, Schoeffel GJ, et al. Effect of vapor lock on root canal debridement by using a side-vented needle for positive-pressure irrigant delivery. J Endod 2010;36(4):745-750. DOI: 10.1016/j. joen.2009.11.022.

6. Gu LS, Kim JR, Ling J, et al. Review of contemporary irrigant agitation techniques and devices. J Endod 2009;35(6):791-804. DOI: 10.1016/j. joen.2009.03.010.

7. Brito PR, Souza LC, de Oliveira JC, et al. Comparison of the effectiveness of three irrigation techniques in reducing intracanal Enterococcus faecalis populations: an in vitro study. J Endod 2009;35(10):1422-1427. DOI: 10.1016/j.joen.2009.07.001.

8. Brunson M, Heilborn C, Johnson DJ, et al. Effect of apical preparation size and preparation taper on irrigant volume delivered by using negative pressure irrigation system. J Endod 2010;36(4):721-724. DOI: 10.1016/j.joen.2009.11.028.

9. Angeles B, Cangemi R. In vitro antibacterial effect of different irriation solutions on Enterococcus faecalis. Acta Odonta Lactinam 2006;19:75-80.

10. Hülsmann M, Peters OA, Dummer PM. Mechanical preparation of root canals: shaping goals, techniques and means. Endodontic topics 2005;10(1):30-76. DOI: 10.1111/j.1601-1546.2005.00152.x.

11. Byström A, Sunvqvist $G$. The antibacterial action of sodium hypochlorite and EDTA in 60 cases of endodontic therapy. Int Endod J 1985;18(1):35-40. DOI: 10.1111/j.1365-2591.1985.tb00416.x.

12. Young GR, Parashos $P$, Messer $\mathrm{HH}$. The principles of techniques for cleaning root canals. Aust Dent J 2007;52:S52-S63. DOI: 10.1111/j.18347819.2007.tb00526.x.

13. Siqueira Jr JF, Rôças IN. Clinical implications and microbiology of bacterial persistence after treatment procedures. J Endod 2008;34(11):1291-1301. DOI: 10.1016/j.joen.2008.07.028.

14. Zehnder M. Root canal irrigants. J Endodontics 2006;32(5):389-398. DOI: 10.1016/j.joen.2005.09.014.

15. Ozdenmir HO, Dongan $\mathrm{H}$, Calt S. Effect of EDTA and $\mathrm{NaOCl}$ on $E$. faecalis biofilm colonization in young and old human root canal dentin: in vitro study. J Endod 2010;36(5):842-846. DOI: 10.1016/j. joen.2010.01.008.

16. Gondim JrE, Setzer FC, Dos Carmo CB, et al. Postoperative pain after the application of two different irrigation devices in a prospective randomized clinical trial. J Endod 2010;36(8):1295-1301. DOI: 10.1016/j. joen.2010.04.012.

17. Bradford CE, Eleazer PD, Downs KE, et al. Apical pressures developed by needles for canal irrigation. J Endodont 2002;28(4):333-335. DOI: 10.1097/00004770-200204000-00019. 
18. Susin L, Liu Y, Yoon JC, et al. Canal and isthmus debridement efficacies of two irrigant agitation techniques in a closed system. Int Endod J 2010;43(12):1077-1090. DOI: 10.1111/j.1365-2591.2010.01778.x.

19. Fukumoto Y, Kikuchi I, Yoshioka T, et al. An ex vivo evaluation of a new root canal irrigation technique with intracanal aspiration. Int Endod J 2006;39(2):93-99. DOI: 10.1111/j.1365-2591.2006.01050.x.

20. Stuart $\mathrm{CH}$, Schwartz SA, Beeson TJ, et al. Enterococcus faecalis: its role in root canal treatment failure and current concepts in retreatment. J Endod 2006;32(2):93-98. DOI: 10.1016/j.joen.2005.10.049.

21. Usman N, Baumgartner JC, Marshall JG. Influence of instrument size on root canal debridement. J Endod 2004;30(2):110-112. DOI: 10.1097/00004770-200402000-00012.

22. Boutsioukis C, Verhaagen $B$, Versluis $M$, et al. Evaluation of irrigant flow in the root canal using different needle types by an unsteady computational fluid dynamics model. J Endod 2010;36(5):875-879. DOI: 10.1016/j.joen.2009.12.026.

23. Desai $P$, Himel V. Comparative safety of various intracanal irrigation systems. J Endod 2009;35(4):545-549. DOI: 10.1016/j.joen.2009.01.011.

24. Haapasalo M, Endal U, Zandi H, et al. Eradication of endodontic infection by instrumentation and irrigation solutions. Endodontic topics 2005;10(1):77-102. DOI: 10.1111/j.1601-1546.2005.00135.x.

25. Nielsen BA, Baumgartner JC. Comparison of the Endovac system to needle irrigation of root canals. J Endod 2007;33(5):611-615. DOI: 10.1016/j.joen.2007.01.020.

26. Vinothkumar TS, Kavitha S, Lakshminarayanan L, et al. Influence of irrigating needle-tip designs in removing bacteria inoculated into instrumented root canals measured using single-tube luminometer. J Endod 2007;33(6):746. DOI: 10.1016/j.joen.2007.02.013. 